\section{Left Dominant Arrythmogenic Cardiomyopathy}

Sir,

Left dominant arrythmogenic cardiomyopathy (LDAC) is a rare genetic entity that is characterised by fibrofatty infiltration, predominantly in the left ventricular myocardium. The characteristic pathological changes include involvement of the left ventricle in contrast to involvement of right ventricular myocardium in ARVC. The clinical presentation could range from fainting episodes, palpitations, and sudden cardiac death. ${ }^{1}$

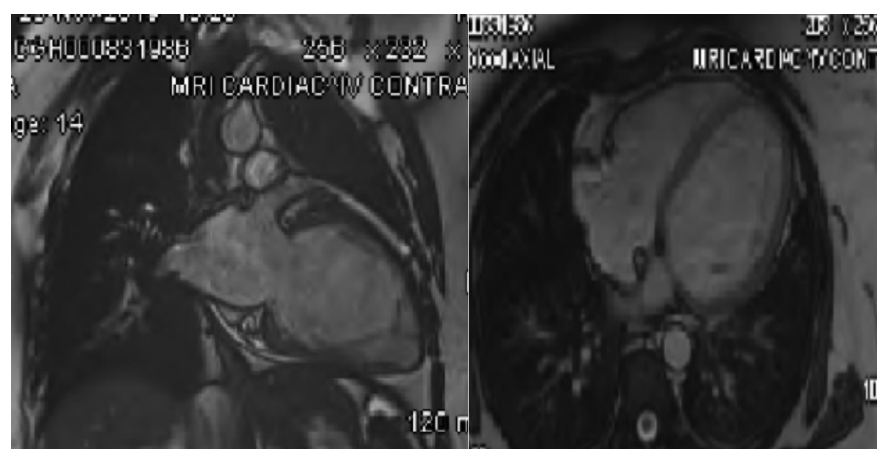

Figure 1: Cardiac MRI showing fibrofatty infiltration involving left ventricle.

We report a middle-age lady presenting with lightheadedness and fatigue. There was no past history of any cardiovascular condition. ECG showed complete heart block, leading to insertion of PPM with ICD. It was decided to investigate it further as it was very unusual for a middle aged lady to present with complete heart block with no previous cardiovascular history. Echocardiography showed low ejection fraction, so a coronary angiogram was requested which revealed non-obstructing arteries. A cardiac MRI scan (CMR) was done eventually, which was diagnostic for $\angle A D C$, with findings of involvement of the left ventricle with significantly impaired left ventricular function and global hypokinesia with disproportionate hypokinesia in the septum and inferior walls (Figure 1). LDAC should be kept in differentials if the involvement is predominantly in the left ventricular and there is no evidence of ischemic causes, myocarditis or any similar condition.

LDAC has been an under-recognised condition as it is either included in advanced arrythmogenic right ventricular cardiomyopathy, misdiagnosed by other conditions like dilated cardiomy- opathy or myocarditis. The diagnosis can be challenging, and echocardiography can be inconclusive in initial stages, and it is leading to underestimation of its prevalence. Cardiac MRI is a helpful investigation in distinguishing between overlapping conditions like infiltrative diseases, cardiac sarcoid or myocarditis. ${ }^{1,2}$ Pathologic examination under the microscope reveals myocytic degeneration, fatty infiltration and fibrosis. ${ }^{3}$ Cardiac magnetic resonance imaging is a diagnostic investigation for this LDAC, and the findings are consistent with predominant involvement of left ventricle. ${ }^{4}$

\section{CONFLITCT OF INTEREST:}

Authors declared no conflict of interest.

\section{AUTHORS' CONTRIBUTION:}

MMS, KA, JC: Conceived, edited and reviewed.

\section{REFERENCES}

1. Sen-Chowdhry S, Syrris P, Prasad SK, Hughes SE, Merrifield $\mathrm{R}$, Ward $\mathrm{D}$, et al. Left-dominant arrhythmogenic cardiomyopathy: An under-recognised clinical entity. J Am Coll Cardiol 2008; 52(25):2175-87.

2. Hamilton-Craig C, McGavigan A, Semsarian C, Martin A, Atherton J, Stanton T, et al. The cardiac society of Australia and New Zealand position statement on the diagnosis and management of arrhythmogenic right ventricular cardiomyopathy (2019 Update). Heart Lung Circ 2020; 29(1):40-8.

3. Miles C, Finocchiaro G, Papadakis M, Gray B, Westaby J, Ensam B, et al. Sudden death and left ventricular involvement in arrhythmogenic cardiomyopathy. Circulation 2019; 139(15):1786-97.

4. Feliu E, Moscicki R, Carrillo L, García-Fernández A, Martínez JG, Ruiz-Nodar JM. Importance of cardiac magnetic resonance findings in the diagnosis of left dominant arrythmogenic cardiomyopathy. Rev Esp Cardiol (Engl Ed) 2020; S1885-5857(19): 30424-4.

Muhammad Mohsin Sajjad, Kabir Ali and John Corrigan

Cavan General Hospital, Ireland

Correspondence to: Dr. Muhammad Mohsin Sajjad, Cavan General Hospital, Ireland

E-mail: drmohsin34567@gmail.com

Received: March 04, 2020; Revised: June 12, 2020;

Accepted: June 26, 2020

DOI: https://doi.org/10.29271/jcpsp.2021.02.244 